\title{
Mediação cultural e de leitura na formação do bibliotecário biblioterapeuta
}

\section{Cultural and reading mediation in the qualification of bibliotherapist librarian}

\section{Mediación cultural y lectora en la formación del bibliotecário biblioterapeuta}

Hélio Márcio Pajeú ${ }^{1, a}$

helio.pajeu@gmail.com | https://orcid.org/0000-0002-0657-1088

Wérleson Alexandre de Lima Santos ${ }^{1, b}$

werleson.ale@gmail.com | https://orcid.org/oooo-0002-4682-6874

${ }^{1}$ Universidade Federal de Pernambuco, Departamento de Ciência da Informação. Recife, PE, Brasil.

a Doutorado em Linguística pela Universidade Federal de São Carlos.

b Bacharelado em Biblioteconomia pela Universidade Federal de Pernambuco.

\section{RESUMO}

O presente artigo visa fazer uma reflexão acerca da formação do bibliotecário na Universidade Federal de Pernambuco (UFPE) como profissional apto para o exercício da mediação cultural e de leitura, bem como da biblioterapia. Tomando como base os conceitos de mediação cultural de Edmir Perrotti e de mediação de leitura de Michèle Petit, o trabalho debruça-se sobre a grade curricular do perfil 0406 do Bacharelado em Biblioteconomia e analisa a distribuição do conteúdo programático, das competências e das cargas horárias e como a formação cultural e biblioterapêutica do discente está sendo tratada em relação à percepção de sua importância sociocultural dentro da atuação profissional.

Palavras-chave: Mediação cultural; Mediação de leitura; Biblioterapia; Saúde mental; Formação profissional do bibliotecário.

\section{ABSTRACT}

This article aims to purpose a reflection over the librarian's qualification at Federal University of Pernambuco (UFPE) as a professional able to exercise cultural and reading mediation, and also bibliotherapy. Based on the theories on cultural mediation by Edmir Perrotti and reading mediation by Michèle Petit, this study leans on the academic curriculum from the Library Science undergraduate course 0406 profile and analyses the program content, the skills teaching, the workload and how the student's cultural and bibliotherapeutic qualification has been treated regarding their perceptions about the professional sociocultural importance.

Keywords: Cultural mediation; Reading mediation; Bibliotherapy; Mental health; Professional qualification of librarians. 


\section{RESUMEN}

Este artículo tiene como objetivo reflexionar sobre la formación del bibliotecario de la Universidad Federal de Pernambuco (UFPE) como profesional capaz de ejercer la mediación cultural y la lectura, así como la biblioterapia. Basado en los conceptos de mediación cultural de Edmir Perrotti y la mediación de lectura de Michèle Petit, el trabajo se enfoca en el plan de estudios del perfil 0406 del grado en Biblioteconomía y analiza la distribución del contenido del programa, habilidades y cargas de trabajo y cómo se trata la formación cultural y biblioterapéutica del alumno en relación con la percepción de su importancia sociocultural dentro del desempeño profesional.

Palabras claves: Mediación cultural; Mediación de la lectura; Biblioterapia; Salud mental; Formación profesional del bibliotecário.

Contribuição dos autores:

Concepção e desenho do estudo: Hélio Márcio Pajeú e Wérleson Alexandre de Lima Santos.

Aquisição, análise ou interpretação dos dados: Wérleson Alexandre de Lima Santos.

Redação do manuscrito: Hélio Márcio Pajeú e Wérleson Alexandre de Lima Santos.

Revisão crítica do conteúdo intelectual: Hélio Márcio Pajeú.

Declaração de conflito de interesses: não há.

Fontes de financiamento: não houve.

Considerações éticas: não há.

Agradecimentos/Contribuições adicionais: não há.

Histórico do artigo: submetido: 11 jun. 2020 | aceito: 7 maio 2021 | publicado: 31 ago. 2021.

Apresentação anterior: não houve.

Licença CC BY-NC atribuição não comercial. Com essa licença é permitido acessar, baixar (download), copiar, imprimir, compartilhar, reutilizar e distribuir os artigos, desde que para uso não comercial e com a citação da fonte, conferindo os devidos créditos de autoria e menção à Reciis. Nesses casos, nenhuma permissão é necessária por parte dos autores ou dos editores. 
Reciis - Revista Eletrônica de Comunicação, Informação \& Inovação em Saúde, Rio de Janeiro, v. 15, n. 3, p. 703-721, jul.-set. 2021 [www.reciis.icict.fiocruz.br] e-ISSN 1981-6278

\section{INTRODUÇÃO}

Antes de partirmos para uma prática profissional, é necessário que reflitamos acerca dos mecanismos que viabilizam essa prática, como também acerca da formação acadêmica que nos põe em contato com esses mecanismos - sejam eles concretos e materiais, relativos à execução profissional; sejam eles subjetivos e não táteis, relacionados à viabilização da prática, ou até mesmo de âmbito teórico, o que permite o reconhecimento dos dois mecanismos supracitados. É necessário que possamos perceber qual caminho foi preparado para nossa formação profissional e como esses mecanismos nos foram apresentados nessa trajetória, de forma que seja possível avaliar de que forma nossa prática profissional se desenvolve e quais outras competências precisam ser demandadas para uma formação mais completa e em diálogo com a realidade imediata com a qual trabalhamos.

Como bibliotecários e profissionais que gerem e mediam (in)formação, nos tornamos agentes de mudança social capazes de alterar a realidade que nos circunscreve, bem como a realidade dos usuários com os quais nos relacionamos no dia a dia da profissão. Temos o poder de indicar caminhos para que os sujeitos possam se tornar críticos e culturalmente empoderados, porém também temos o poder de cuidar daqueles que estão em situação de fragilidade social por meio das ações culturais que promovemos. A biblioterapia surge como uma ação ao alcance dos bibliotecários que lhes dá o poder de atuar nos campos da saúde mental, ajudando na reabilitação e restauração de sujeitos emocionalmente feridos.

A biblioterapia parte de um conceito mais amplo: a mediação cultural. Definir mediação cultural de uma forma esquemática, fechada, é um desafio, visto que existem nuances e contextos a serem levados em consideração. Numa perspectiva mais radical, podemos caracterizá-la como a criação de pontes entre os sujeitos e os objetos de cultura (PERROTTI; PIERUCCINI, 2014). Ela é uma maneira de lidar com os conflitos socioculturais que envolvem o acesso e a apropriação dos bens culturais pelos sujeitos.

O objetivo principal da mediação cultural é permitir que os indivíduos, os grupos e as coletividades possam se apropriar de seus bens culturais, desenvolvendo um protagonismo, não apenas uma relação de consumo, possibilitando o exercício da cidadania cultural em plenitude. Realizar a mediação cultural é permitir que aqueles sujeitos que foram postos à margem da esfera cultural possam se apropriar do que lhes é de direito, o que ajuda na composição de suas identidades culturais, permitindo que esses mesmos sujeitos sejam retirados da categoria de simples consumidores e espectadores do jogo cultural. Entendese que essa mediação proporcionará uma tomada de consciência, afinal eles também têm direitos sobre esses bens, e possibilitará que eles sejam protagonistas desse jogo, de forma que possam produzir e ter os elementos que compõem a formação e atuação da malha cultural da sociedade.

A mediação cultural não é feita de uma única forma. Por isso, Dufrêne e Gellerau (2004 apud LIMA; PERROTTI, 2016, p.163-164) nos dizem que há “dois níveis de mediação - o da manifestação da mediação em atividades dos profissionais para e com um público, e o das políticas de desenvolvimento dessas ações culturais". E complementam que "para entendermos ou explicarmos as práticas de mediação é preciso que nos coloquemos numa perspectiva sociológica, admitindo pensar a mediação cultural como sistema de mediações" (DUFRÊNE; GELLERAU, 2004 apud LIMA; PERROTTI, 2016, p.164). Isso implica refletir que quando se fala de mediação cultural, fala-se de uma rede de ações, explícitas ou implícitas, que agem em prol da garantia do protagonismo cultural pela população, de acordo com os autores citados.

Em questões mais concretas, as ações explícitas são aquelas nas quais os atores são vistos de forma clara e em que as ações de intermediação podem ser sentidas de maneira mais evidente (ALMEIDA JUNIOR, 2009). Como exemplos, temos o programa Cine Sesi Cultural, que exibe filmes em cidades do interior do Brasil; ou o Som na Rural, projeto em que um veículo leva música para diversas localidades da cidade do Recife. Já as ações implícitas são aquelas nas quais a mediação não pode ser vista de maneira evidente e 
têm caráter mais estrutural (ALMEIDA JUNIOR, 2009). Aqui, podemos citar o modo como as bibliotecas organizam e disponibilizam os seus acervos, desde a forma como os livros estão dispostos nas estantes, em expositores ou numa seção de 'novas aquisições'.

A mediação cultural, contudo, não se limita a dar acesso - também cria as condições ideais para que os sujeitos possam ter esse acesso a uma apropriação cultural. Portanto, "a mediação cultural é o ato de criar condições culturais e cognitivas para os embates entre atores e signos” (LIMA; PERROTTI, 2016, p. 167). Ela surge como negociação para um conflito social em que há sujeitos que não possuem as condições ideais de acesso aos bens culturais; ela negocia esse conflito a partir da criação de formas, situações e condições que permitam o acesso, a assimilação, a ressignificação e a apropriação de saberes e objetos culturais, bem como da cultura em si. Afinal,

[...] não se trata tão somente de fazer a transmissão ou permitir o acesso aos signos. É preciso criar vínculos simbólicos entre os diferentes espaços de transição, pontos de convivência que tornam possível o 'viver juntos', em especial em época de mudanças que alteram relações de tempo e espaço, via tecnologias virtuais cada vez mais onipresentes na experiência cotidiana, em escala global. (PERROTTI; PIERUCCINI, 2014, p. 11)

A criação de condições ideais e a tentativa de diminuir as barreiras sociais que impedem que a cidadania cultural seja exercida em plenitude devem ser realizadas considerando-se que o objeto cultural é, muitas vezes, visto como algo distante do alcance dos sujeitos postos à margem. Torna-se necessário também a tentativa da criação de um vínculo entre o sujeito e o objeto e o bem cultural, de forma que o primeiro possa se ver no segundo e sentir-se pertencente a ele.

Os objetos culturais são signos e, mais que isso, 'discursos' potencialmente capazes de produzir deslocamentos intelectuais, emocionais, afetivos, [...] constituem-se como realidades concretas e objetivas, permeadas e dividindo o espaço social com outros fenômenos e sujeitos. (PERROTTI; PIERUCCINI, 2014, p. 8)

A partir da mediação cultural outras mediações irão surgir, dando enfoque a cada um dos tipos de manifestações culturais. É com essa ferramenta que o bibliotecário dá voz a sujeitos marginalizados, criando as condições para um levante pessoal e social. Porém, para que o profissional possa fazê-lo, é necessário que ele tenha entrado em contato com a teoria e tido a oportunidade de explorar suas nuances durante a sua formação, bem como tenha tido o olhar despertado para um cuidado mais íntimo e subjetivo de seus usuários - algo que vai além da simples disponibilização de materiais de informação e que recai sobre questões de olhar o outro como um sujeito único e se perceber enquanto parte de um possível processo de cura mental. Esse processo se refere não somente aos bibliotecários hospitalares, mas também aos escolares, públicos, especializados etc., enfim, qualquer profissional que mantenha um contato direto com outros seres humanos.

Diante disso, surge uma questão: estariam nossas universidades preparadas para formar bibliotecários mediadores culturais? Ou mais: estariam nossas universidades aptas a desenvolver bibliotecários biblioterapeutas com empatia o bastante para olhar o outro além de uma mera necessidade informacional? Partindo disso, o presente estudo visa fazer uma análise do Projeto Político-Pedagógico do Bacharelado em Biblioteconomia da Universidade Federal de Pernambuco (UFPE) de forma a avaliar o tratamento que o perfil 0406 vem dando às questões culturais do fazer bibliotecário. Não obstante, pretendemos também realizar um breve levante teórico do que tange as questões da biblioterapia e da mediação de leitura tomando como base principal os estudos desenvolvidos por Michèle Petit -, de forma a apresentarmos um arcabouço teórico que seja suficiente para sustentar a análise posteriormente realizada. 


\section{ALÉM DE UMA MEDIAÇÃO CULTURAL: A MEDIAÇÃO DE LEITURA}

A mediação cultural, como bem-vista anteriormente, pode se dar em toda e qualquer manifestação concreta da esfera da cultura. Ela é ampla e engloba todas as manifestações culturais da sociedade. Dentro dessas manifestações, podemos encontrar a literatura e, por consequência, a leitura. A mediação de leitura é mediação cultural e, sendo assim, é um ato de responsabilidade. Ela tem o poder de atingir leitores em potencial e de aproximá-los definitivamente do mundo literário, ou o contrário, de afastá-los, dependendo da forma como for feita.

Para mediar leitura, temos que levar em consideração que ela "é influenciada por um contexto mais amplo, um ambiente que convida ou desestimula a aproximar-se dos livros" (PETIT, 2009, p. 149) e que não deve ser feita de maneira descompromissada. Mediar leitura é criar uma ponte para que sujeitos sejam capazes de construir mundos internos e fornecer a eles as ferramentas necessárias para a compreensão do mundo externo. Mediar leitura é abrir portas para uma edificação interior e para uma constante reconstituição da própria identidade.

A mediação de leitura coloca o indivíduo em contato com sua própria linguagem, que nada mais é que o instrumento maior de compreensão e exercício da vida social. Ao fazê-lo, seja de forma direta ou indireta, o mediador está fornecendo os meios necessários para que o leitor possa ver e construir seus próprios caminhos, tanto na vida pessoal, como indivíduo único em constante jornada, quanto na vida social, como sujeito socialmente organizado pertencente a uma dinâmica sociocultural de relações. Permitir que o sujeito entre em contato com sua própria linguagem é permitir que ele possua esses meios de mudança e de constituição identitária e social, pois

[...] a apropriação da língua, o acesso ao conhecimento, como também a tomada de distância, a elaboração de um mundo próprio, de uma reflexão própria, propiciados pela leitura, podem ser o pré-requisito, a via de acesso ao exercício de um verdadeiro direito de cidadania. Pois os livros roubam um tempo do mundo, mas eles podem devolvê-lo, transformado e engrandecido, ao leitor. E ainda sugerir que podemos tomar parte ativa no nosso destino. (PETIT, 2009, p. 148)

A mediação de leitura é um jogo de sedução no qual o mediador passa paixão e gosto pela leitura e pelo escrito e tenta convencer o leitor a se aventurar por entre as páginas daquele livro. São necessários afeto e cuidado e o estabelecimento de uma relação amigável entre as partes. Acima de tudo, promover a leitura como caráter obrigatório, apresentando-a ao leitor como um dever, pode afastá-lo e dificultar uma possível aproximação literária.

Existem maneiras de mediar leitura que podem ir desde a simples indicação de um livro até o ato de ler para alguém, todavia a chave para uma mediação não está apenas no ambiente em que ela é realizada, mas também na pessoa que está assumindo o papel de mediador. Petit (2009) afirma que o mediador tem o poder de legitimar um ato de leitura. A partir do momento em que um sujeito indica um livro para alguém, ou simplesmente possibilita que esse alguém leia o que ele quiser, está tornando oficial o ato leitor e está permitindo que essa pessoa se sinta livre para expressar seus desejos literários sem preocupação com determinações ou deveres.

O mediador aqui tem um papel difícil, que é o de resgate. Petit (2009) também afirma que durante a trajetória de todo o ser humano haverá momentos que podem causar um afastamento da leitura. A autora chama esses momentos de 'umbrais'. Esses umbrais criam barreiras que atrapalham o progresso da constituição do sujeito leitor. Com isso, a autora afirma que o mediador não só inicia a leitura, mas também acompanha esse trajeto de forma a encontrar maneiras de impedir que os tais umbrais se sobreponham. As origens dos umbrais são variadas, porém muitas estão relacionadas às questões socioeconômicas dos leitores em potencial que minam o acesso aos dispositivos de leitura por parte das classes menos favorecidas. 
Existem cuidados a serem tomados ao mediar leitura. Um deles é o mediador não impor suas ideologias e seus gostos pessoais ao indicar um livro ou realizar uma leitura. Sobre isso, Petit (2013) acrescenta:

Muitas vezes, nos meios onde ler não é habitual, os mediadores tentam chamar atenção das pessoas com livros que supostamente têm a ver com elas. Porém, depois, nem sempre lhes dão a oportunidade de passar para outra coisa, de ampliar seu universo cultural. Então os vemos condenados a voltarem sempre ao seu ponto de partida. (PETIT, 2013, p. 26)

É necessário permitir que o leitor evolua em suas preferências literárias, fornecendo-lhe novos horizontes a serem explorados, além daquele que foi seu ponto de partida. Não devemos limitar a experiência leitora de alguém com base no que nós cremos ser bom; é imprescindível a existência de um diálogo entre leitor e mediador no qual haja um companheirismo nas relações mediadas. O mediador passa a leitura ao sujeito, que responde de maneira afirmativa ou negativa, e o sujeito comunica ao mediador suas preferências, curiosidades, estigmas e receios, de modo que a mediação possa ser feita de uma maneira em que ambas as partes possam se expor e se compreender. Mediar leitura é estabelecer um diálogo e uma relação de amizade.

A mediação de leitura deve ser algo livre e fluído, sem compromissos e deveres. O leitor deve ficar livre para percorrer as mais diversas gamas da esfera literária, permitindo uma constante evolução e, sempre, respeitando o tempo e as nuances dele. Ler é tomar posse da própria língua. E, a partir dessa posse, o sujeito é capaz de compreender o mundo à sua volta e compreender a si mesmo; é capaz de entender os fenômenos sociais, políticos e culturais que o circundam e identificar qual seu lugar dentro desse orbe. Acima de tudo, tomar posse da língua é poder construir sua identidade, destruí-la e reconstruí-la quantas vezes forem necessárias, possibilitando constante mudança e o constante engrandecimento intelectual e pessoal.

Mediar leitura é garantir que os sujeitos se apropriem de sua própria linguagem de forma que se tornem capazes de protagonizarem sua própria cidadania cultural, bem como tenham os meios necessários para desenvolver um novo mundo dentro e fora de si, além de permitir uma autocompreensão e um novo descobrimento de cada experiência. Mediar leitura é construir uma ponte entre o sujeito e o mundo e entre o sujeito e ele próprio.

Freire (2008, p. 20) nos diz que: "[...] a leitura da palavra não é apenas precedida pela leitura do mundo, mas por uma certa forma de 'escrevê-lo' ou de 'reescrevê-lo', quer dizer, de transformá-lo através de nossa prática consciente". Ou seja, ao ler e escrever, o leitor revive seu passado e reescreve de maneira subjetiva o que lê, a partir do momento em que a experiência de leitura se encontra com seu acervo de memórias. A leitura, para Freire, é uma maneira de nos conectarmos com o mundo à nossa volta, de nos sentirmos parte dele, pois é através da palavra que nós podemos estabelecer relações com o mundo. Ela é uma continuidade da leitura e vivência no mundo.

Ao ler, podemos associar nossas vivências na vida com nossas vivências na palavra, e, a partir dessa conexão, podemos estabelecer sentidos ao que vivenciamos em ambos os mundos. Desta forma, ler nos permite utilizar os conhecimentos da palavra para entender a realidade, usar os conhecimentos da realidade para respaldar a palavra, para então utilizar essas vivências como formas de desenvolvimento interno e subjetivo e como mecanismo de edificação do sujeito crítico, autoconsciente e socialmente ativo.

\section{BIBLIOTERAPIA E LEITURA RESTAURADORA}

Como já mencionado, a leitura tem um papel de construção e reconstrução de nós mesmos, de nossos mundos, de nossas identidades. Quando estamos 'quebrados' e sem esperanças em relação ao mundo à nossa volta, ler, muitas vezes, pode abrir o caminho para nossa reabilitação e consequente melhora. $\mathrm{O}$ ato de ler pode agir como uma espécie de válvula de escape, de modo que o leitor possa se resguardar dentro 
de um mundo outro, no qual suas fantasias e seus desejos são aflorados, um lugar propício à reflexão de si mesmo, ao seu (re)conhecimento - para que possa encontrar, então, a estrada que o levará para fora de seu estado atual.

A leitura restauradora serve para recuperar o sujeito em crise, para colocá-lo em trabalho de introspecção e de imaginação.

Na leitura há algo mais do que o prazer, algo que é da ordem de um ‘trabalho psíquico' [...] que permite encontrar um vínculo com aquilo que nos constitui, que nos dá lugar, que nos dá vida. [...] Quando a pessoa se sente despedaçada, quando o corpo é atingido, angústias e fantasias arcaicas são despertadas, e a reconstrução de uma representação de si, de sua interioridade, pode ser vital. E, nas leituras, ou também na contemplação de obras de arte, há algo que pode ser profundamente reparador. (PETIT, 2013, p. 68)

Ler em momentos de crise pessoal é uma maneira de se reconectar com o mundo, seja por meio de uma leitura de ficção, seja por meio de algo que fale diretamente sobre o que estamos passando. Petit (2013) traz relatos acerca desse papel restaurador da leitura, como o caso da menina Carlota, uma bebê prematura que estava sob cuidados em um hospital, cujos médicos repararam que suas taxas de controle se normalizavam e se estabilizavam sempre que sua mãe ia lhe contar histórias; ou o caso do autor Bernhard, cuja leitura de 'Os demônios' de Dostoiévski lhe deu forças para querer se recuperar e buscar novas obras. As obras, numa leitura restauradora, não necessariamente precisam falar sobre o que está acometendo o leitor ou trazer uma identificação imediata com algum personagem - elas precisam, factualmente, despertar no leitor sentimentos de conforto e fornecer a ele a força para sair de seu estado e procurar novos horizontes.

Seja em coletivo, mediada, ou de maneira solitária, a leitura restauradora serve como aliada na reabilitação de sujeitos acometidos por males como doenças, lutos, perdas e frustrações. Partindo desse princípio, a biblioterapia surge como uma ação restauradora para sujeitos em dificuldades.

Ouaknin (1996 apud BORTOLIN; SILVA, 2016) define biblioterapia como "a terapia por meio de livros". Silva (2014, p. 45) traz uma definição mais poética: "uma terapia da alma que se faz por meio de textos literários". Ela age por meio da mediação de leitura para indivíduos com algum tipo de enfermidade ou acometidos por algum outro mal, como uma prescrição de medicações literárias.

Com a biblioterapia é possível nortear o leitor e levá-lo para outro ambiente, inseri-lo em locais nunca vistos, possibilitando sensações, vibrações de um mundo muitas vezes inexplorado. Dependendo do gênero do livro que será narrado pode provocar lembranças antigas, relacionar fatos antes desconhecidos. (BORTOLIN; SILVA, 2016, p. 53-54)

A biblioterapia visa mostrar ao sujeito em dificuldade que ele não está só e tenta recuperá-lo provendo conforto e distração por meio das ações de intervenção. Ela quebra o ambiente e o estado frio em que o leitor se encontra e fornece-lhe momentos de distração e lazer. O biblioterapeuta é o mediador que vai fornecer os insumos ao leitor, porém o grande foco da biblioterapia - e o que vai agir diretamente nos males que acometem os sujeitos - é a relação que esses sujeitos irão estabelecer com os textos lidos e com as ações culturais realizadas, uma vez que "devido ao poder que as palavras e as imagens têm de evocar emoções pretéritas, a leitura desperta emoções positivas e negativas, que poderão influenciar na forma como percebemos o mundo" (SILVA; ANDRADE NETA, 2005, p. 1174).

Apesar de não ser o único protagonista da biblioterapia, o biblioterapeuta tem um papel fundamental para uma boa mediação de leitura restauradora. O diálogo que ele estabelecerá com os leitores é extremamente importante. Eles devem se sentir ouvidos, compreendidos, acolhidos, e jamais devem ser forçados a ler algo ou a passar por uma intervenção que não desejem. São necessários um cuidado especial, empatia, humanidade e abdicação de quaisquer vaidades que possam interferir nas ações. 
O mediador nesse caso está agindo por altruísmo e por vontade de ajudar um sujeito em estado fragilizado; ele jamais deve impor suas vontades e precisa estar disposto a ouvir as respostas desse leitor, de forma que possam juntos desenvolver as atividades necessárias para uma reabilitação saudável, uma vez que:

[...] eu me mostro ao outro e o outro se mostra para mim, com tanta intensidade e persistência que minha individualidade e a individualidade do outro abdicam do singular e cedem lugar à universalidade. [...] Ao realizar as atividades de biblioterapia, entende-se que o outro não se apresenta de frente, quer dizer, ele não mostra sua verdadeira face, receia não ser amado pelo que é, posto que tem defeitos e idiossincrasias. O cuidado se manifesta, então, na preocupação em tranquilizar o outro, em mostrar que não se está fazendo julgamento de condutas nem impondo uma norma de comportamento. (CALDIN, 2009, p. 67)

O biblioterapeuta deve trabalhar para construir um ambiente familiar e amistoso, que convide o leitor à participação e que proporcione sensações de alívio e acolhimento (CALDIN, 2009, p. 67). É como um grande abraço depois de um dia ruim. Deve-se ter em mente que o sujeito para o qual estamos nos direcionando está em uma situação de fragilidade emocional e psicológica que o coloca na defensiva e mina sua autoestima. Destaca-se que, para muitos, os dias são extremamente solitários e aquele será o único momento de contato realmente humano com outra pessoa. É necessário amor, compaixão, empatia e dedicação.

Outro cuidado a ser tomado com os leitores é em relação à escolha das obras. Não há como realizar uma mediação de leitura com qualquer texto, sem responsabilidade com o ambiente e os sujeitos que lá estão, pois as histórias, como já dito, têm ligação com nosso emocional e com nossas lembranças, de tal forma que "assim como pode gerar uma força para não se deprimir, também poderá ser determinante para transmitir ainda mais ansiedade e tristeza" (BALBINOTTI, 2017, p. 33). A escolha das obras é algo a ser feito com muito cuidado, pois temas mais delicados como abandono, violência dos mais variados tipos, abusos e morte podem ser gatilhos para despertar traumas antigos e piorar de maneira preocupante o estado do leitor.

Contudo, é necessário que o mediador também tome certas precauções consigo mesmo antes de realizar uma intervenção biblioterapêutica. Ele necessita ter em mente que estará entrando em um ambiente doente com seres em situações delicadas, portanto precisa estar saudável física e mentalmente, de forma que o ambiente não o afete em demasia, tornando-se melancólico e até adoecendo.

Existem diversos tipos de biblioterapia, e de acordo com Pereira (1996 apud SILVA, 2014) destacam-se três:

1. Biblioterapia institucional: realizada de maneira individual com pacientes internados, cujas obras são escolhidas por um bibliotecário em parceria com uma equipe médica com propósitos recreativos e informativos. As obras são escolhidas de maneira direcionada para cada paciente participante.

2. Biblioterapia clínica: as obras são de 'literatura imaginativa' e são escolhidas por um médico ou bibliotecário, agindo de maneira individual ou em conjunto, com foco em pessoas acometidas por problemas emocionais, cujo objetivo é a mudança de comportamento.

3. Biblioterapia desenvolvimental: realizada por um bibliotecário, professor ou outro profissional, com foco em pessoas sem nenhum tipo de enfermidade ou transtorno mental diagnosticado, mas que são acometidas por adversidades (como preconceitos diários, divórcios, lutos etc.). Um de seus objetivos é a manutenção da saúde mental.

Além disso, a biblioterapia não tem como instrumentos de trabalho apenas livros - ela também "utiliza outras ferramentas, contemplando as várias formas de leitura, por exemplo, de textos não verbais (jogos, imagens, vídeos, música)" (BENTES PINTO, 2005, p. 39), de forma que as sessões sejam mais lúdicas e permitam uma melhor interação entre pacientes e biblioterapeuta - evitando, assim, uma relação unilateral 
na qual apenas um dos indivíduos age e permitindo uma relação plural, na qual todos os envolvidos participam ativamente das sessões e das atividades realizadas.

Ao valer-se de leitura, narração, dramatização, brincadeiras, jogos, música, dança e diálogo, a preocupação dos aplicadores da biblioterapia é com o bem-estar do ser total, com o fortalecimento dos fatores formadores do equilíbrio e com a eliminação das perturbações (que não são acontecimentos isolados, mas se encontram em um contexto cultural, social e histórico). (CALDIN, 2009, p. 75)

A biblioterapia pode ser aplicada tanto num contexto de saúde física (como mediações em setores de oncologia ou geriatria de hospitais), como num contexto de saúde mental. Sobre a questão da saúde mental, há estudos realizados por pesquisadores tanto da área de Psicologia como da área de Biblioteconomia que comprovam a eficácia do tratamento biblioterapêutico dentro do quadro da saúde mental.

Há contradições acerca do uso da leitura no tratamento de pacientes psicológicos, como bem mostra Silva (2014) em seu trabalho. Entretanto, a pesquisadora realizou um estudo prático dentro de uma unidade de tratamento com pacientes acometidos por transtornos mentais, como o Transtorno Bipolar e o Transtorno Obsessivo Compulsivo, em que se verificaram progressos positivos. A pesquisadora constatou que depois da realização de seis sessões de biblioterapia, os pacientes demonstraram uma melhora em seus estados "tendo-se estes recreado, refletido sobre os seus problemas, sentimentos e emoções, através dos textos lidos, seus comentários em grupo aos mesmos, através das atividades escritas e atividades lúdicas que foram realizadas" (SILVA, 2014, p. 186).

A pesquisadora também afirma que foi perceptível uma sensação de bem-estar dos pacientes durante as sessões e após o término delas. Além disso, Silva também afirma que houve uma melhora na comunicação entre os pacientes e no compartilhamento de sentimentos e emoções entre eles, que se sentiram mais confortáveis em expor aspectos pessoais.

Diante disso, podemos esperar que a biblioterapia seja usada por profissionais da saúde e bibliotecários no auxílio à redução do sofrimento físico e psicológico que acomete sujeitos das mais variadas instâncias. Bentes Pinto (2005) nos lembra que é necessária a parceria entre esses dois profissionais para que o tratamento dê certo e reforça que a leitura sem o acompanhamento terapêutico não se traduz em biblioterapia. Ela necessita do acompanhamento profissional para evitar possíveis quadros de piora ou o surgimento de gatilhos emocionais de eventos traumáticos.

Mediar leitura para um sujeito em sofrimento emocional requer compaixão. É estar diante da alteridade destituído de preconceitos e barreiras, é ajudar alguém, possibilitar que esse sujeito encontre conforto em meio a seu caos mental. É ter uma relação de empatia, na qual biblioterapeuta e paciente trabalham juntos, permitem-se serem tocados, abrem espaço entre si, para que um se veja no outro, contemplando a própria humanidade e permitindo a construção de uma ponte para longe das sombras da tristeza e da dor.

\section{ANÁLISE DA FORMAÇÃO DO BIBLIOTECÁRIO NA UNIVERSIDADE FEDERAL DE PERNAMBUCO}

Tendo em vista as discussões realizadas anteriormente, chegamos ao momento de nos questionar acerca das habilidades que constituem bons mediadores culturais e biblioterapeutas. Sendo assim, devemos realizar uma análise do Projeto Político-Pedagógico Curricular (PPC) do curso de Biblioteconomia da UFPE.

Destarte, podemos nos apoiar novamente nos escritos de Petit (2009), quando a autora nos traz uma série de características e ações a serem encontradas em bibliotecários mediadores, quais sejam:

- Ser hospitaleiro ao leitor, tornando a experiência de leitura algo encantador.

- Conhecer seu leitor, seus gostos e suas preferências. 
- Evitar promover a leitura como obrigação. É preciso respeitar a individualidade do leitor. O mediador jamais deverá impor seus gostos pessoais.

- Garantir que o leitor tenha acesso a escolhas. Fornecer-lhe opções de leitura, deixando-o livre para ler o que ele quiser. ${ }^{1}$

- Realizar um acompanhamento do leitor, permitir seu crescimento, levá-lo por outros vieses literários, se assim ele desejar.

- A relação estabelecida com o leitor é de diálogo. Deve-se evitar que ele entenda que seu espaço pessoal está sendo invadido. O que deve ser lido é o que de fato é bom para o leitor, e não o que se acredita que seja.

- Um bom conhecimento de literatura facilita a sugestão, seleção e disseminação de obras, seja por solicitação do leitor, seja por iniciativa do próprio bibliotecário.

- A mediação de leitura deve ser fluida e jamais determinada por modelos fixos e limitantes.

Essas mesmas características definidas por Petit podem ser aplicadas a qualquer outro tipo de manifestação cultural, já que ela, assim como a mediação de leitura, visa ao protagonismo cultural do cidadão. Diante dessas perspectivas, podemos nos questionar se nossas escolas de Biblioteconomia estão realmente formando bibliotecários mediadores. Em decorrência disso, buscamos analisar o PPC do curso de graduação em Biblioteconomia da Universidade Federal de Pernambuco (2011) e avaliar que tratamento é dado à formação do bibliotecário como mediador cultural e de leitura.

O perfil vigente na UFPE no momento de concepção deste estudo é o 0406, e seu PPC aborda de que maneira o curso de Biblioteconomia deverá preparar seus alunos. Em seu marco teórico-conceitual, o documento trata da questão sociocultural na formação bibliotecária ao mencionar, por exemplo, a ocupação dos equipamentos de cultura por meio da criação de bibliotecas nas comunidades periféricas. Devido ao descaso por parte do poder público no que tange a essa questão, a necessidade de capacitação de profissionais com temáticas que abordem os mais variados tipos de bibliotecas e as questões das ações culturais para a promoção de uma apropriação cultural ganham relevância. Sobretudo, mais explicitamente, ao mencionar que a formação do profissional "deve prepará-lo como agente de mediação cultural contribuindo para a redução das assimetrias entre indivíduos ou grupos e os bens simbólicos em contextos sociais específicos" (UFPE, 2011, p. 12).

Acerca dos objetivos gerais, a mediação cultural aparece explícita em apenas um dos cinco objetivos citados: "Elaborar, coordenar, executar e avaliar planos, programas e projetos ligados à informação e cultura" (UFPE, 2011, p. 14). Dessa forma, o curso visa formar o bibliotecário como um instigador do protagonismo sociocultural de maneira que, ao elaborar, coordenar e executar projetos de disseminação cultural, o profissional possa auxiliar as comunidades carentes no acesso aos objetos e aos saberes de cultura. Isso fica claro ao se observarem os objetivos específicos: apenas um dos seis aborda a questão da mediação cultural, qual seja: "Elaborar e realizar atividades culturais de promoção e democratização da informação em bibliotecas e em outros dispositivos culturais" (UFPE, 2011, p. 14).

Ainda acerca da questão cultural no trabalho do bibliotecário, o texto aborda o perfil profissional daqueles que se pretende formar ao dizer, por exemplo, que o graduado deve ser: "[...] motivado para acompanhar a evolução do conhecimento científico, artístico e cultural, voltado para uma prática profissional criativa;

1 Importante lembrar que esse critério é utilizado para mediações culturais e de leitura num contexto mais geral. Na questão da biblioterapia, há uma limitação nesse quesito, uma vez que algumas obras são passíveis de despertar traumas e servir como gatilhos emocionais. Dessa forma, ao mediar a leitura para um sujeito em fragilidade emocional, é feita uma seleção prévia das obras, e o sujeito é livre para transitar entre elas. 
comprometido com o desenvolvimento sociocultural e científico-tecnológico no contexto onde atua” (UFPE, 2011, p. 16).

Embora haja um entendimento das urgências atuais, das implicações sociais e de saúde na formação do bibliotecário cultural, a disposição da grade curricular do curso não reflete tal compreensão. Apenas uma disciplina do ciclo básico (Informação e Sociedade), entre nove, e uma do ciclo profissional (Políticas de Informação e Cultura), entre 23, são capazes de lidar com tal natureza. A maior concentração de disciplinas que lidam com esse tema se encontra nos componentes eletivos (seis num total de 37 eletivas). Observa-se que há um claro desequilíbrio na distribuição dessas disciplinas - um desacordo com uma das propostas do PPC para a área cultural.

Apesar de demonstrar interesse nessa área, a grade curricular reflete uma clara preferência por uma formação tradicional ainda tecnicista, voltada para o tratamento documental, deixando o teor social da formação bibliotecária em segundo plano.

\section{Quadro 1 - Disciplinas de mediação de leitura e cultural}

\begin{tabular}{|l|l|l|}
\hline Disciplina & Código & Ciclo \\
\cline { 1 - 2 } Informação e Sociedade & BI597 & \multirow{2}{*}{ Ciclo básico (obrigatório) } \\
\cline { 1 - 2 } Políticas de Informação e Cultura & BI605 & $\begin{array}{l}\text { Ciclo profissional } \\
\text { (obrigatório) }\end{array}$ \\
\cline { 1 - 2 } Aç̃̃es, Instituições e Bens Culturais & BI617 & \multirow{2}{*}{ Componente eletivo } \\
\cline { 1 - 2 } Cultura Brasileira 1 & LE741 & \\
\cline { 1 - 2 } História da Cultura & HI277 & \\
\cline { 1 - 2 } Mediação da Informação e Relações Etnicorraciais & BI653 & \\
\cline { 1 - 2 } Seminários de Leitura & BI630 & BI632 \\
\cline { 1 - 2 } Tipologias de Bibliotecas & \multicolumn{2}{|l}{} \\
\hline
\end{tabular}

Fonte: elaboração dos autores.

Ao avaliar as ementas das disciplinas, as que melhor dialogam com a temática da mediação cultural são: Mediação da Informação e Relações Etnicorraciais; Políticas de Informação e Cultura; Ações, Instituições e Bens Culturais; e Seminários de Leitura. Para fins de melhor análise, as chamaremos aqui de 'disciplinas de atuação cultural'.

Já Informação e Sociedade; Tipologias de Bibliotecas; Cultura Brasileira 1; e História da Cultura servem para dar o embasamento teórico necessário para uma mediação cultural de qualidade - aqui elas serão chamadas de 'disciplinas de embasamento cultural'.

As 'disciplinas de atuação cultural' dialogam acerca do papel do bibliotecário agindo diretamente na sociedade por meio da intervenção e da mediação cultural. Baseado no perfil curricular 0406 do curso (UFPE, 2019), pode-se dizer que os temas versam sobre: as instituições produtoras de cultura e os seus papéis dentro da dinâmica social; as relações dessas instituições com as comunidades; a relação da informação com nichos sociais e como ela colabora para a formação de uma identidade social e, por consequência, cultural; o dever das instâncias de poder dentro da esfera cultural da sociedade; as maneiras que o bibliotecário, como mediador cultural e agente de mudança social, poderá intervir para permitir que os sujeitos postos à margem possam se inserir e, consequentemente, protagonizar suas próprias culturas a partir da elaboração e da análise de políticas e projetos culturais para tal fim; os textos como produção de sentido e como elementos de constituição identitária, de compreensão do mundo, da sociedade e das relações dos sujeitos com eles mesmos e com os outros. 
Essas quatro disciplinas (Mediação da Informação e Relações Etnicorraciais; Políticas de Informação e Cultura; Ações, Instituições e Bens Culturais; e Seminários de Leitura) se encaixam dentro dos parâmetros estabelecidos por Petit para a formação de um bom mediador. Ao abordarem as nuances das relações entre cultura e sujeitos e como um mediador pode facilitar essa relação, as disciplinas colaboram para a formação de um bibliotecário crítico sobre seu papel na sociedade e como formador de outros sujeitos críticos e conscientes.

As 'disciplinas de embasamento cultural' servem como apoio para o bom desempenho dos conhecimentos apreendidos nas disciplinas já mencionadas. Essas disciplinas ajudam a compreender a dinâmica social que arquiteta a informação e as relações dela com a cultura, bem como esse percurso cultural ao longo da história da humanidade e como a cultura se configura nos dias de hoje. Promovem também o embasamento necessário para que os profissionais conheçam as mais variadas formas de bibliotecas, sendo capazes de desenvolver projetos e ações culturais voltados para essas tipologias.

Apenas esse nicho de componentes curriculares não basta para uma abordagem eficaz acerca da formação de um bibliotecário mediador cultural e de leitura, sobretudo quando atentamos para o fato de que apenas duas delas são de conteúdo obrigatório. A formação do bibliotecário na UFPE, nesse quesito, está deficitária, tornando-se necessária a criação de mais disciplinas obrigatórias que atentem para esse aspecto da composição profissional.

Indo mais adiante, em se tratando da formação do bibliotecário como biblioterapeuta, apenas a disciplina Seminários de Leitura atende de alguma forma a esse propósito. O conteúdo programático da disciplina versa sobre os diversos tipos de leitura e as diversas formas de ler, o texto como elemento produtor de sentidos, a literatura de modo alargado e o leitor como sujeito ativo nessa produção. Apesar disso, existem outros componentes curriculares ofertados na graduação de Biblioteconomia da UFPE que poderiam servir como base para o estabelecimento de debates acerca do papel do bibliotecário no âmbito da saúde e, em especial, da saúde mental, como mostra o quadro a seguir.

Para uma melhor organização dos papéis que as disciplinas poderiam desempenhar, elas foram divididas em três eixos: 'disciplinas de atividades relacionadas', 'disciplinas de atividades aplicadas' e ‘disciplinas de desenvolvimento específico'. Sendo assim: 


\section{Quadro 2-Disciplinas para o desenvolvimento da Biblioterapia}

\begin{tabular}{|c|c|c|}
\hline Disciplina & Caráter de oferta & Eixo \\
\hline Serviço de Referência e Informação & Obrigatório & \multirow{3}{*}{$\begin{array}{l}\text { Disciplinas de atividades } \\
\text { relacionadas }\end{array}$} \\
\hline Usuários da Informação & \multirow{2}{*}{ Eletivo } & \\
\hline Informação em Saúde & & \\
\hline Políticas de Informação e Cultura & Obrigatório & \multirow{3}{*}{ Disciplinas de atividades aplicadas } \\
\hline Ações, Instituições e Bens Culturais & \multirow{2}{*}{ Eletivo } & \\
\hline Tipologias de Bibliotecas & & \\
\hline Informação e Sociedade & \multirow{3}{*}{ Obrigatório } & \multirow{6}{*}{$\begin{array}{l}\text { Disciplinas de desenvolvimento } \\
\text { específico }\end{array}$} \\
\hline Estágio Supervisionado & & \\
\hline $\begin{array}{l}\text { Práticas em Biblioteconomia e Ciência da } \\
\text { Informação }\end{array}$ & & \\
\hline Seminários de Leitura & \multirow{3}{*}{ Eletivo } & \\
\hline $\begin{array}{l}\text { Tópicos Especiais em Recursos e Serviços de } \\
\text { Informação }\end{array}$ & & \\
\hline Tópicos Especiais em Biblioteconomia & & \\
\hline
\end{tabular}

Fonte: elaboração dos autores.

As 'disciplinas de atividades relacionadas' recebem este nome devido ao fato de suas ementas não deixarem explícito que uma atividade direcionada ao âmbito da saúde mental, a indivíduos deprimidos, possa ser realizada; não há diretrizes explícitas para a formação de um bibliotecário dentro desse âmbito, porém os conteúdos ministrados na disciplina podem servir como base para um estudo aplicado na área posteriormente.

Explicamos melhor: um dos objetivos que constam da ementa da disciplina Serviço de Referência e Informação é: "A interação e a colaboração. Atendimento e educação do usuário" (UFPE, [2013?]a). Partindo desse objetivo, o professor que ministrar tal disciplina pode incentivar o aluno a seguir os estudos com foco na saúde mental, a conhecer as maneiras de estabelecer um diálogo com um usuário, atendendo às suas necessidades e realizando um serviço de referência especializado. Porém, como a disciplina é relacionada, o estudante que desejar se apropriar de fato dos conhecimentos no tocante à questão deverá buscar apoio acadêmico em outras disciplinas que possam complementar a experiência e a aprendizagem.

Por sua vez, a disciplina Usuários da Informação tem em sua ementa: "Estudo do perfil do usuário. Identificação das necessidades do usuário" (UFPE, [2013?]b). O estudante que opta por cursar tal componente aprenderá as maneiras de identificar as necessidades de um usuário para realizar um melhor serviço. O professor pode optar por realizar atividades que visem ao estudo de usuários acamados em hospitais, bem como deixar livre para que os próprios alunos realizem tal atividade, se assim desejarem. Independentemente de as atividades direcionadas serem ou não realizadas, a ementa da disciplina dá conta de preparar o estudante para conhecer as necessidades de outro sujeito. Aqueles que desejarem trabalhar e/ou estudar o tema de maneira mais direcionada poderão procurar disciplinas em outros cursos para completar a experiência. Esta disciplina serve de complemento à anterior (Serviço de Referência e Informação).

E muito embora as disciplinas não prevejam em suas ementas de maneira clara as relações entre serviço de referência/estudo de usuários e biblioterapia, Silva (2014, p. 50) antecipa que a biblioterapia é uma forma de serviço de referência (o que a autora vem chamar de 'aconselhamento de leituras') ao afirmar que: 
"a biblioterapia pode ser vista como uma forma aperfeiçoada da função de aconselhamento de leituras, ou, por outras palavras, o aconselhamento de leituras é como se fosse uma forma rudimentar de biblioterapia”. Dessa forma, os conhecimentos lecionados em ambas as disciplinas podem colaborar para a formação do bibliotecário biblioterapeuta.

Por fim, a disciplina que talvez melhor dialogue diretamente com o tema é Informação em Saúde, porém sua ementa visa mais a formação de um bibliotecário gestor de informações em saúde do que de um agente de atuação intervencionista. Dentro das temáticas de saúde abordadas no conteúdo programático, a questão da saúde mental pode ser mencionada e fornecer ao estudante conhecimentos úteis para realizar as ações de intervenção cultural nas unidades de tratamento psicossocial. Contudo, por se voltar mais para uma visão tecnicista da produção, uso e fluxo da informação nesses ambientes, a formação do biblioterapeuta não será bem desenvolvida no componente em questão.

O segundo eixo, 'disciplinas de atividades aplicadas', diz respeito aos componentes curriculares que dialogam com a questão da biblioterapia e da mediação cultural e de leitura em contextos de saúde mental, mas elas não são necessariamente abordadas em seu conteúdo programático. Entretanto, atividades aplicadas no contexto de biblioterapia podem ser realizadas pelo professor no transcorrer do semestre letivo.

A disciplina Políticas de Informação e Cultura já foi avaliada em parágrafos anteriores como uma das que mais colaboram para a formação do bibliotecário mediador cultural. Ela também apresenta potencial para a formação do bibliotecário biblioterapeuta num contexto de saúde mental, ao versar sobre políticas e projetos culturais voltados para nichos sociais. O professor que lecionar a disciplina poderá realizar atividades com a elaboração de projetos culturais voltados para intervenções em clínicas de reabilitação psicossocial, assim como ações voltadas para a Rede de Atenção Psicossocial (RAPS) e para projetos culturais que dialoguem com a Agenda de Ações Estratégicas para a Vigilância e Prevenção do Suicídio e Promoção da Saúde no Brasil 2017 a 2020 (BRASIL, 2017), elaborada pelo Ministério da Saúde (ou outros planos e projetos semelhantes). Ao realizar essas ações, o aluno que se interessar pela biblioterapia terá aptidão e conhecimento prático para elaborar projetos que usem a biblioterapia e as ações culturais de leitura e mediação como ferramentas em hospitais e em ambientes de fragilidade emocional e social, como é o caso dos asilos.

Em seguida, tanto Tipologias de Bibliotecas quanto Ações, Instituições e Bens Culturais servem da mesma forma ao bibliotecário biblioterapeuta na UFPE. As duas também já foram vistas de maneira positiva, enquanto formadoras de mediadores culturais e, portanto, os professores que as lecionarem poderão abordar as bibliotecas hospitalares e as ações culturais. Ao falar de depressão, por exemplo, os professores podem orientar os alunos quanto à criação de atividades e ações em instituições de cultura - não necessariamente em ambientes hospitalares - que possam abordar a promoção da saúde mental, a prevenção ao suicídio e o combate à depressão.

O terceiro e último eixo, 'disciplinas de desenvolvimento específico', é composto pelas disciplinas cujas ementas e cujos conteúdos programáticos abrem um espaço claro para o debate acerca das questões de biblioterapia, informação e saúde mental e da atuação do bibliotecário nesses ambientes.

A primeira delas - Informação e Sociedade - possui em sua ementa como um dos objetivos de debate: "Inclusão social e democratização da informação" (UFPE, [2013?]c). Partindo desse objetivo, a questão dos indivíduos acometidos por transtornos mentais - como a depressão -, que se encontram afastados do convívio social e, por consequência, longe da dinâmica informacional e interativa da sociedade, pode proporcionar um debate sobre como os bibliotecários podem agir para reinserir esses sujeitos na sociedade, proporcionando uma reabilitação sociocultural. Debater qual o papel do bibliotecário como agente de mudança numa sociedade deprimida e com altas taxas de suicídio, bem como qual o papel da informação e 
de sua consequente disseminação na melhora ou piora dos quadros clínicos, é algo fundamental. A forma como esses conteúdos podem 'percorrer' as disciplinas, para que ocorram de fato a prevenção efetiva e a conscientização coletiva acerca do tema, é, na nossa opinião, algo basilar.

As disciplinas Estágio Supervisionado e Práticas em Biblioteconomia e Ciência da Informação buscam fazer com que o aluno exerça atividades práticas relacionadas à área e podem servir como um laboratório para que os estudantes realizem essas atividades no Hospital das Clínicas da UFPE, proporcionando a eles uma experiência com a biblioterapia. As disciplinas podem ajudar os graduandos a ganhar experiência com as atividades biblioterapêuticas, ao identificarem maneiras de agir dentro do âmbito da saúde no tocante às questões de mediação de leitura por meio de ações culturais nas dependências do hospital com os acamados e os acompanhantes.

Seminários de Leitura, disciplina eletiva cuja ementa já foi mencionada, trata da leitura como lugar de produção de sentidos. Aqui, a biblioterapia pode ser encarada de maneira específica, considerando-se o desenvolvimento de atividades de mediação de leitura em ambientes de fragilidade, o poder da leitura restauradora etc. É a disciplina de toda a grade curricular que melhor se encaixa na formação de um biblioterapeuta.

Por fim, os Tópicos Especiais em Biblioteconomia e os Tópicos Especiais em Recursos e Serviços de Informação podem ser úteis para alargar os debates acerca do tema. Tratam-se de disciplinas eletivas dispostas em quatro modalidades cujas suas temáticas são ditadas a gosto do professor, a partir de assuntos que o mesmo julgar pertinentes.

Com os Tópicos Especiais em Recursos e Serviços de Informação, os professores poderiam abordar a formação de um bibliotecário de referência para a área de saúde e as suas competências, trazendo um debate acerca da função do bibliotecário em ambientes hospitalares e permitindo a abertura de horizontes de atuação para os estudantes ao mostrar que o bibliotecário, enquanto disseminador da informação nesses ambientes, atua em contato direto com transtornos mentais, como a depressão.

Já os Tópicos Especiais em Biblioteconomia são a oportunidade para uma disciplina que trate, efetivamente, de biblioterapia, de acordo com os moldes de disciplinas já ministradas no curso de Biblioteconomia da Universidade Federal do Rio de Janeiro (ALVES, 2017), na qual o tema é tratado em suas nuances teóricas e práticas, ao discutir, de maneira mais profunda e detalhada, os tipos de biblioterapia, suas aplicações e as competências necessárias para a atuação de um biblioterapeuta.

Todas as disciplinas mencionadas podem auxiliar o debate acerca do tema e despertar e incentivar estudantes que porventura desejem essa experiência. Entretanto, visto que apenas três delas são de caráter obrigatório e que a oferta das demais depende das demandas e decisões internas da gestão do curso, o debate e a formação de profissionais aptos em biblioterapia figuram como algo extremamente difícil. Existem disciplinas em outros cursos da UFPE - Campus Recife -, e o estudante interessado pode procurar por elas para desenvolver aptidões, para se tornar um biblioterapeuta e, assim, atuar em questões de saúde mental. 
Quadro 3-Disciplinas de demais cursos da UFPE - Campus Recife

\begin{tabular}{|c|c|c|c|}
\hline Disciplina & $\begin{array}{l}\text { Caráter de } \\
\text { oferta }\end{array}$ & Curso & Centro acadêmico \\
\hline Processos Socioafetivos & \multirow{4}{*}{ Obrigatório } & \multirow{8}{*}{ Psicologia } & \multirow{9}{*}{$\begin{array}{l}\text { Centro de Filosofia } \\
\text { e Ciências Humanas } \\
\text { (CFCH) }\end{array}$} \\
\hline Processos Psicossociais & & & \\
\hline Psicopatologia & & & \\
\hline Teorias para Intervenção Grupal & & & \\
\hline $\begin{array}{l}\text { Abordagem Psicossomática do } \\
\text { Comportamento Humano }\end{array}$ & \multirow{4}{*}{ Eletivo } & & \\
\hline Intervenções Psicossociais & & & \\
\hline Práticas de Intervenção em Grupo & & & \\
\hline Psicologia Hospitalar & & & \\
\hline Antropologia das Emoções 1 & Eletivo & $\begin{array}{l}\text { Ciências Sociais } \\
\text { (Bacharelado e } \\
\text { Licenciatura) }\end{array}$ & \\
\hline Psicologia Social & Obrigatório & Serviço Social & $\begin{array}{l}\text { Centro de Ciências } \\
\text { Sociais Aplicadas (CCSA) }\end{array}$ \\
\hline Uso Social da Informação & Obrigatório & Gestão da Informação & $\begin{array}{l}\text { Centro de Artes e } \\
\text { Comunicação (CAC) }\end{array}$ \\
\hline
\end{tabular}

Fonte: elaboração dos autores baseado em UFPE (2018; 2013d; 2013e; 2013f; 2013g)

Acredita-se que, cursando essas disciplinas, o graduando interessado obterá conhecimentos que possam muni-lo de informações acerca do desenvolvimento e comportamento da mente humana, fornecendolhe sensibilidade o bastante para se tornar um biblioterapeuta apto a realizar ações de intervenções e desenvolver atividades biblioterapêuticas no tratamento de transtornos mentais.

Tornar-se um biblioterapeuta é algo muito individual e parte dos desejos pessoais de cada um. É uma atividade nobre que busca fornecer conforto para sujeitos em situação de fragilidade emocional. O desenvolvimento de habilidades que busquem a sensibilidade e a empatia necessárias para que tais feitos sejam realizados é algo primordial para uma biblioterapia saudável e eficaz.

\section{CONSIDERAÇÕES FINAIS}

Como foi visto, a leitura tem um poder de mudança interna, capaz de construir um novo eu dentro de um indivíduo 'quebrado' que acredita ter se perdido há muito tempo. Ela abre portas para a reflexão, para a autocompreensão e para a reabilitação sociocultural dos sujeitos. A mediação cultural surge também criando condições para que os sujeitos possam entrar em contato com sua própria cultura e se sintam parte dela, servindo como mecanismo de reabilitação e resgate sociocultural.

É engano pensar que apenas a leitura salvará o indivíduo - esse é um trabalho conjunto no qual ela prestará apenas um papel. Esse é um trabalho de amigos, familiares, psicólogos, psiquiatras e bibliotecários, que vão estender a mão para o sujeito e ajudá-lo nessa caminhada tortuosa e difícil para longe dos efeitos de doenças da mente.

Como bibliotecários, mediadores culturais inseridos num contexto social cheio de pormenores e em constante mudança, devemos nos atentar a essa gama de sujeitos muitas vezes escanteados e que estão aumentando em número com o passar do tempo. Existem ações que podem ser feitas em qualquer tipologia 
de biblioteca para quebrar o estigma acerca dos transtornos mentais e do suicídio, com o objetivo de informar, auxiliar na detecção de sujeitos nessa situação e, consequentemente, contribuir para a promoção da saúde mental. Citamos algumas delas:

- A realização de simpósios, palestras e debates com psicólogos e assistentes sociais acerca da depressão e do suicídio, esclarecendo dúvidas e quebrando estigmas. Essa ação poderia ser realizada em qualquer tipologia de biblioteca, porém, poderia ser especialmente realizada em bibliotecas públicas e de alcance maior de grupos maiores.

- A promoção de palestras com dicas sobre os cuidados a serem tomados com a saúde mental, promovendo-as em contextos familiares e comunitários.

- Para bibliotecas escolares, a realização de rodas de diálogos entre pais e profissionais especializados na área da Psicologia com o intuito de explanar sobre a depressão e o suicídio na infância e na adolescência, como forma de prevenir tais situações e fornecer aos pais a capacidade de identificar possíveis sintomas em seus filhos.

- A informação sobre locais de tratamento gratuito ou de baixo custo para famílias menos favorecidas juntamente com telefones úteis e demais detalhes necessários para a promoção da saúde mental.

- A realização de sessões de meditação coletiva e atividades de relaxamento em grupo.

- Para bibliotecas universitárias, a realização de conversas sobre a saúde mental em ambientes acadêmicos e o fornecimento de serviços e informações para sujeitos acometidos por males mentais e que estão necessitando de ajuda.

- Em ambientes empresariais, a realização de debates acerca da promoção da saúde mental em ambientes de trabalho.

São ações que podem ser realizadas por qualquer bibliotecário em qualquer tipologia de biblioteca e acabam sendo muito úteis para o auxílio na promoção da saúde mental da sociedade e na prevenção da depressão e de outros transtornos mentais.

Além disso, é necessário lembrar que é dever do Estado garantir um serviço de saúde mental público e de qualidade para a população, fornecendo apoio psiquiátrico e psicológico para aqueles que necessitam. Não só isso, como é dever dele também prover o acesso à leitura para as comunidades carentes e para a população geral, por meio do financiamento e da valorização das bibliotecas públicas e escolares, permitindo uma democratização não só da leitura, como da informação e do conhecimento.

Ademais, os bibliotecários que estão sendo formados nas universidades, em especial na UFPE, precisam ser incentivados à função de mediadores culturais e de leitura e à função de agentes de mudança social. As poucas disciplinas obrigatórias que constam da grade curricular não são o bastante para garantir isso. É necessária uma reavaliação da forma como a academia está tratando o fator cultural da biblioteconomia e quais as questões sociais que estão em voga no momento e que dizem respeito à nossa atuação enquanto profissionais.

Ler para alguém em dor é construir uma ponte para fora dos males, é fornecer um ombro amigo a alguém que chora, é dar conforto a quem muito necessita. Mas, principalmente, é mostrar ao outro que ele não está só, que ainda há esperança no fim de tudo e que há um mundo muito mais belo longe de toda a tristeza pronto para ser descoberto, visto, sentido, vivido e, por fim, lido. 
Reciis - Revista Eletrônica de Comunicação, Informação \& Inovação em Saúde, Rio de Janeiro, v. 15, n. 3, p. 703-721, jul.-set. 2021 [www.reciis.icict.fiocruz.br] e-ISSN 1981-6278

\section{REFERÊNCIAS}

ALMEIDA JUNIOR, Oswaldo Francisco. Mediação da informação e múltiplas linguagens. Tendências da Pesquisa Brasileira em Ciência da Informação, Brasília, DF, v. 2, n. 1, p. 89-103, jan.-dez., 2009. Disponível em: https://revistas.ancib.org/index.php/tpbci/article/view/170. Acesso em: 02 jul. 2021.

ALVES, Marilia Amaral Mendes. Biblioterapia: uma experiência inovadora no curso de Biblioteconomia da UNIRIO. Revista Brasileira de Biblioteconomia e Documentação, São Paulo, v. 13, p. 2065-2077, 2017. Trabalho apresentado no $27^{\circ}$ Congresso Brasileiro de Biblioteconomia, Documentação e Ciência da Informação, 2017, Fortaleza. Disponível em: https://rbbd.febab.org.br/rbbd/article/view/1021. Acesso em: 29 nov. 2019

BALBINOTTI, Stheve. Páginas ansiosas: uma viagem pelo oceano da ansiedade até desembarcar na ilha da biblioterapia. Biblionline, João Pessoa, v. 13, n. 1, p. 43-50, jan.-mar. 2017. DOI: https://doi.org/10.22478/ ufpb.1809-4775.2017v13n1.32891. Disponível em: http://www.periodicos.ufpb.br/ojs/index.php/biblio/article/ view/32891. Acesso em: 26 nov. 2018.

BENTES PINTO, Vírginia. A biblioterpia como campo de atuação para o bibliotecário. Transinformação, Campinas, v. 17, n. 1, p. 31-43, jan.-abr., 2005. Disponível em: http://www.scielo.br/scielo.php?script=sci abstract\&pid=S0103-37862005000100003\&Ing=en\&nrm=iso\&tlng=pt. Acesso em 26 nov. 2018.

BRASIL. Ministério da Saúde. Agenda de ações estratégicas para a vigilância e prevenção do suicídio e promoção da saúde no Brasil: 2017 a 2020. Brasília, DF: Ministério da Saúde, 2017. 34 p. Disponível em: http://portalarquivos2.saude.gov.br/images/pdf/2017/setembro/21/17-0522-cartilha---Agenda-Estrategicapublicada.pdf. Acesso em: 28 jan. 2021.

BORTOLIN, Sueli; SILVA, Sandra da. Biblioterapia no âmbito hospitalar. Informação@Profissões, Londrina, v. 5, n. 1, p. 52-74, jan.-jun. 2016. DOI: http://dx.doi.org/10.5433/2317-4390.2016v5n1p52. Disponível em: http://www.uel.br/revistas/uel/index.php/infoprof/article/view/24468. Acesso em: 15 set. 2018.

CALDIN, Clarice Fortkamp. Leitura e terapia. 216 f. 2009. Tese (Doutorado em Literatura) - Universidade Federal de Santa Catarina, Florianópolis, 2009.

FREIRE, Paulo. A importância do ato de ler: em três artigos que se completam. 49. ed. São Paulo: Cortez, 2008.

LIMA, Celly de Brito; PERROTTI, Edmar. Bibliotecário: um mediador cultural para a apropriação cultural. Informação@Profissões, Londrina, v. 5, n. 2, p. 161-180, jul.-dez. 2016. DOI: http://dx.doi.org/10.5433/23174390.2016v5n2p161. Disponível em: http://www.uel.br/revistas/uel/index.php/infoprof/article/view/28319. Acesso em: 19 nov. 2018.

PERROTTI, Edmir; PIERUCCINI, Ivete. A mediação cultural como categoria autônoma. Informação \& Informação, Londrina, v. 19, n. 2, p. 1-22, maio-ago. 2014. DOI: http://dx.doi.org/10.5433/19818920.2014v19n2p01. Disponível em: http://www.uel.br/revistas/uel/index.php/informacao/article/view/19992. Acesso em: 19 nov. 2018.

PETIT, Michèle. Leitura: do espaço íntimo ao espaço público. São Paulo: Editora 34, 2013.

PETIT, Michèle. Os jovens e a leitura: uma nova perspectiva. São Paulo: Editora 34, 2009.

SILVA, Ana Mafalda Carvalho. Biblioterapia aplicada em contexto de saúde mental: um estudo de caso. 2014. 215 f. Dissertação (Mestre em Ciências Documentais) - Universidade Lusófona de Humanidades e Tecnologias, Lisboa, 2014.

SILVA, Lindomar Coutinho da; ANDRADE NETA, Nair Floresta. Leitura e saúde emocional. In: CONGRESSO INTERNACIONAL DAABRALIN, 4., 2005, Brasília, DF. Anais [...]. Brasília, DF: [s. n.], 2005. p. 1169-1177. Disponível em: https://www.abralin.org/site/wp-content/uploads/2013/02/anaiscongresso05.pdf. Acesso em: 15 set. 2018.

UNIVERSIDADE FEDERAL DE PERNAMBUCO (UFPE). Departamento de Ciência da Informação. Projeto político-pedagógico do curso de graduação em Biblioteconomia. Recife: DCI, 2011. Disponível em: https://biblioteconomiaufpe.wordpress.com/projetopedagogico/ppc-de-biblioteconomia-perfil-0406/. Acesso em: 30 nov. 2018. 
UNIVERSIDADE FEDERAL DE PERNAMBUCO (UFPE). Departamento de Ciência da Informação. Projeto político-pedagógico do curso de graduação em Gestão da Informação. Recife: DCl, 2018. Disponível em: https://www.ufpe.br/documents/39179/0/Perfil_103.1.pdf/f3b699b8-29d1-476f-af18-c459bd936421. Acesso em: 27 jul. 2021.

UNIVERSIDADE FEDERAL DE PERNAMBUCO (UFPE). Pró-reitoria para assuntos acadêmicos. Diretoria de Desenvolvimento do Ensino. [Ementa da disciplina Serviço de Referência e Informação]. Recife: Próreitoria para assuntos acadêmicos, [2013?]a. Disponível em: https://biblioteconomiaufpe.files.wordpress. com/2012/01/servic3a7os-de-referc3aancia-e-informac3a7c3a3o.pdf. Acesso em: 28 jan. 2021.

UNIVERSIDADE FEDERAL DE PERNAMBUCO (UFPE). Pró-reitoria para assuntos acadêmicos. Diretoria de Desenvolvimento do Ensino. [Ementa da disciplina Usuários da Informação]. Recife: Pró-reitoria para assuntos acadêmicos, [2013?]b. Disponível em: https://biblioteconomiaufpe.files.wordpress.com/2012/01/ usuc3a1rios-da-informac3a7c3a3o.pdf. Acesso em: 28 jan. 2021.

UNIVERSIDADE FEDERAL DE PERNAMBUCO (UFPE). Pró-reitoria para assuntos acadêmicos. Diretoria de Desenvolvimento do Ensino. [Ementa da disciplina Informação e Sociedade]. Recife: Pró-reitoria para assuntos acadêmicos, [2013?]c. Disponível em: https://biblioteconomiaufpe.files.wordpress.com/2012/01/ informac3a7c3a3o-e-sociedade1.pdf. Acesso em: 28 jan. 2021.

UNIVERSIDADE FEDERAL DE PERNAMBUCO (UFPE). Pró-reitoria para assuntos acadêmicos. [Perfil curricular do curso de Bacharelado em Biblioteconomia]. Recife: Pró-reitoria para assuntos acadêmicos, 2019. Disponível em: https://www.ufpe.br/documents/39158/0/PERFIL+CURRICULAR+2019.pdf/ef5c4a1adbe1-4df2-ba3f-80021869833f. Acesso em: 27 jul. 2021.

UNIVERSIDADE FEDERAL DE PERNAMBUCO (UFPE). Pró-reitoria para assuntos acadêmicos. [Perfil curricular do curso de Bacharelado em Ciências Sociais]. Recife: Pró-reitoria para assuntos acadêmicos, 2013d. Disponível em: https://www.ufpe.br/documents/38970/411209/ciencias sociais bacharealdo perfil 1803.pdf/1c4110f3-d944-4bc8-8f17-5d9bf1129077. Acesso em: 27 jul. 2021.

UNIVERSIDADE FEDERAL DE PERNAMBUCO (UFPE). Pró-reitoria para assuntos acadêmicos. [Perfil curricular do curso de Bacharelado em Psicologia]. Recife: Pró-reitoria para assuntos acadêmicos, 2013e. Disponível em: https://www.ufpe.br/documents/498533/0/psicologia_perfil_6613.pdf/dca371f8-ac99-4bff-871c07c92ad2a94d. Acesso em: 27 jul. 2021.

UNIVERSIDADE FEDERAL DE PERNAMBUCO (UFPE). Pró-reitoria para assuntos acadêmicos. [Perfil curricular do curso de Bacharelado em Serviço Social]. Recife: Pró-reitoria para assuntos acadêmicos, 2013f. Disponível em: https://www.ufpe.br/documents/39390/0/servico social perfil 1404.pdf/537eb082-ae134b9f-b8d2-6a100caa1dcb. Acesso em: 27 jul. 2021.

UNIVERSIDADE FEDERAL DE PERNAMBUCO (UFPE). Pró-reitoria para assuntos acadêmicos. [Perfil curricular do curso de Licenciatura em Ciências Sociais]. Recife: Pró-reitoria para assuntos acadêmicos, 2013g. Disponível em: https://www.ufpe.br/documents/38970/411209/ciencias sociais licenciatura perfil_1902.pdf/d252f7e9-faea-4291-8537-66a9ad6c19f5. Acesso em: 27 jul. 2021. 